\title{
ESRC-DFID Raising Learning Outcomes in Education Systems
}

$\mathrm{E} \cdot \mathrm{S} \cdot \mathrm{R} \cdot \mathrm{C}$ ECONOMIC \& S OCIA L RESEARCH 1.

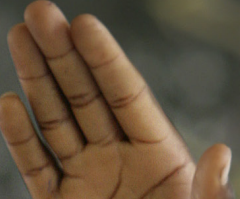

C OUN C I L

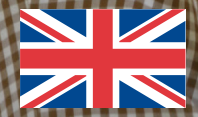

In: 1.

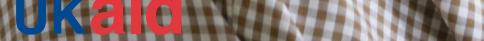


Cover photo: Schoolchildren in Zimbabwe.

(c) Giacomo Pirozzi/Panos 


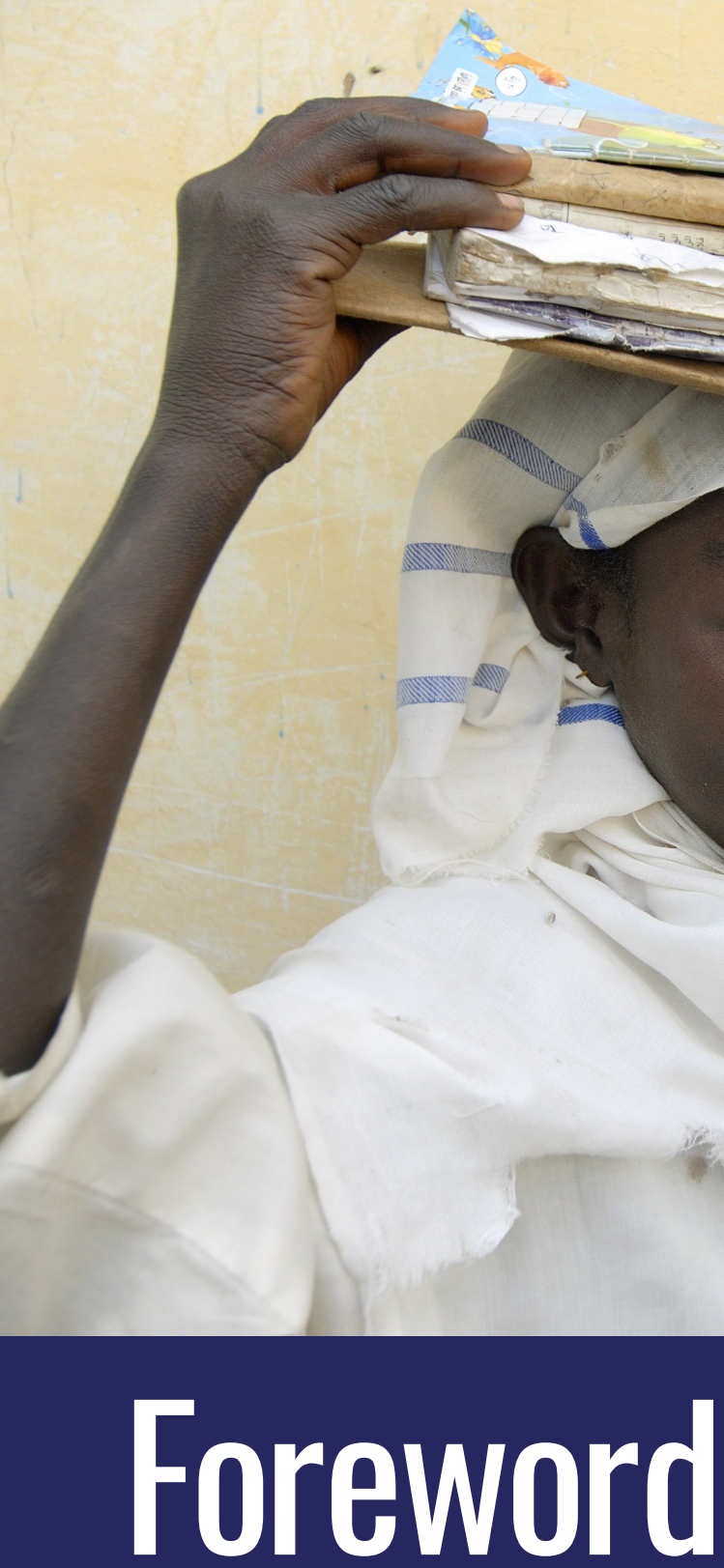




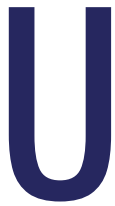

nderstanding how to raise learning outcomes at scale is a global priority, highlighted by the education Sustainable Development Goal (SDG 4). Over 90 per cent of primary-age children in low-income countries cannot read nor do basic maths by the end of primary school. ${ }^{1}$ Business as usual will not deliver the transformational change that is needed. ${ }^{2}$

The ESRC-DFID Raising Learning Outcomes in Education Systems (RLO) Research Programme aims to fill-in critical evidence gaps on the questions of how education systems can work better to overcome the global learning crisis and raise learning outcomes at scale in developing countries. This unique partnership's 30 world-class research grants are producing innovative, rigorous, and policy-relevant research on how to raise learning outcomes globally.

\section{DFID's 2018 Education Policy Get} Children Learning sets out three key pillars: (1) invest in good teaching, (2) back system reform which delivers results in the classroom, and (3) step up targeted support to the most marginalised. The rigorous RLO evidence that is emerging aligns with these policy-relevant, critical themes; for example, how to step up targeted support to marginalised groups such as children with disabilities, children affected by crises, and hard-to-reach girls; system reform which delivers results in the classroom and makes education systems more accountable, effective, and inclusive; and good-quality teaching. The policy seeks to ensure investments are based on robust evidence. RLO research is supporting the design and implementation of DFID education programming, centrally and in country, to drive up education quality globally.

Key questions asked by the programme have been framed around a systems framework focusing on elements, context, and dynamics. Research has focused on three core themes: effective teaching, challenging contexts, and accountability mechanisms. It aims to provide policymakers and practitioners with concrete recommendations on how to improve learning outcomes and an understanding of how these will

\section{D. \\ This unique partnership's 30 world-class research grants are producing innovative, rigorous, and policy-relevant research on how to raise learning outcomes globally. W}

\footnotetext{
${ }^{1}$ http://uis.unesco.org/sites/default/files/documents/fs46-more-than-half-children-not-learning-en-2017.pdf ${ }^{2}$ https://assets.publishing.service.gov.uk/government/uploads/system/uploads/attachment_data/ file/685536/DFID-Education-Policy-2018a.pdf
} 


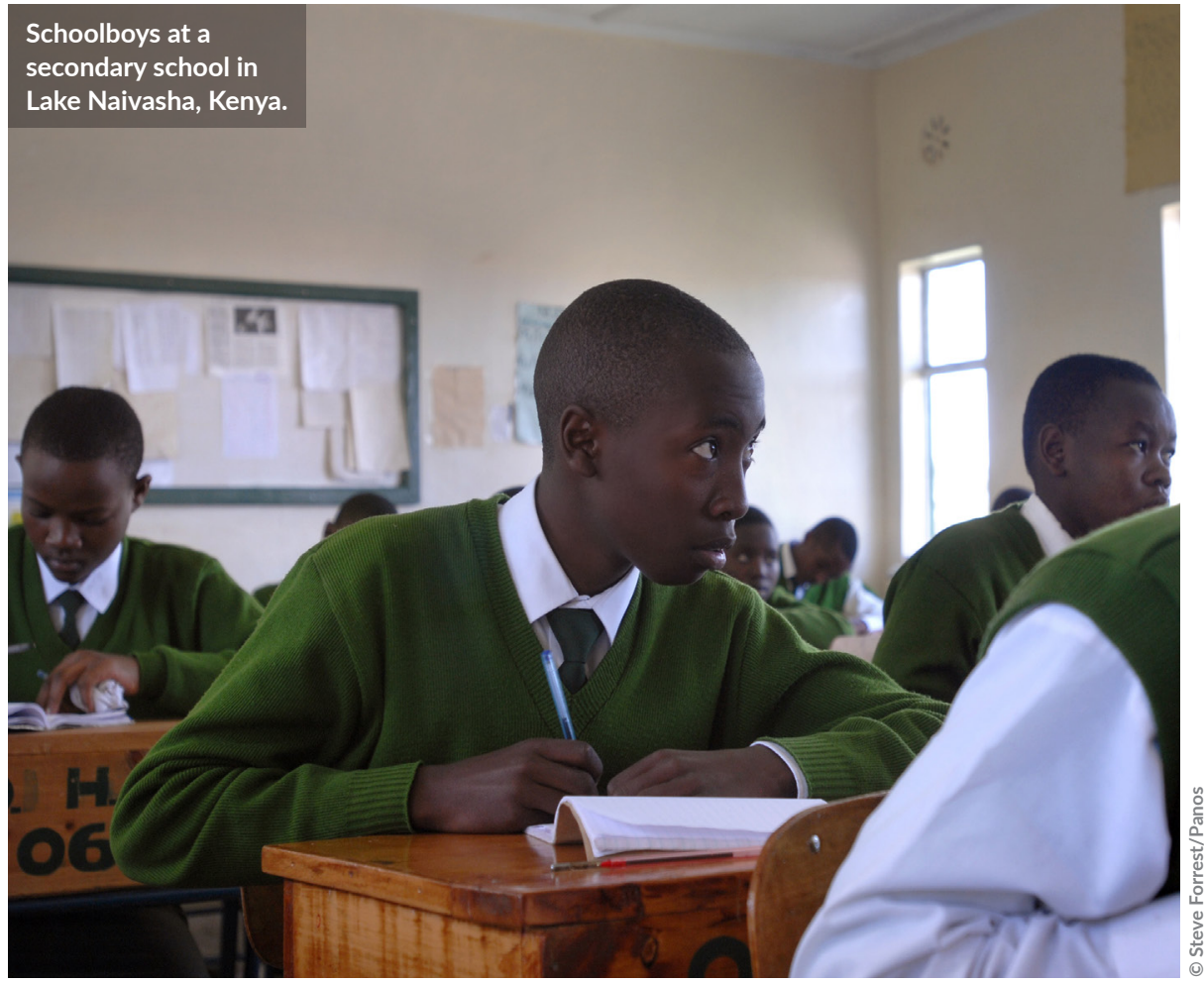

translate to their specific context and institutions.

Collections of evidence on teaching and disability across continents have been synthesised by the RLO programme to meet policy interest and demand. In addition, methodological innovations have been published to continue to develop the multidisciplinary and mixed methods rigour of the field.

The RLO programme is recognised for its unique features, which include: high levels of flexibility and innovation; focus on policy-relevance; strong cross-programme dialogue learning between researchers; and good partnerships with and capacitybuilding of Southern researchers.

DFID and ESRC are delighted with the success of the RLO programme to date, and we welcome this publication as an opportunity to showcase the diverse range of innovative grants we have funded that are starting to answer the critical question 'How can we raise learning outcomes globally?'

\section{Laura Savage}

Deputy Team Lead

DFID Education Research Team 


\section{ESRC-DFID Raising Learning}

Research on raising learning outcomes funded by the UK's Economic and Social Research Council (ESRC) and the Department for International Development (DFID) Strategic Partnership.

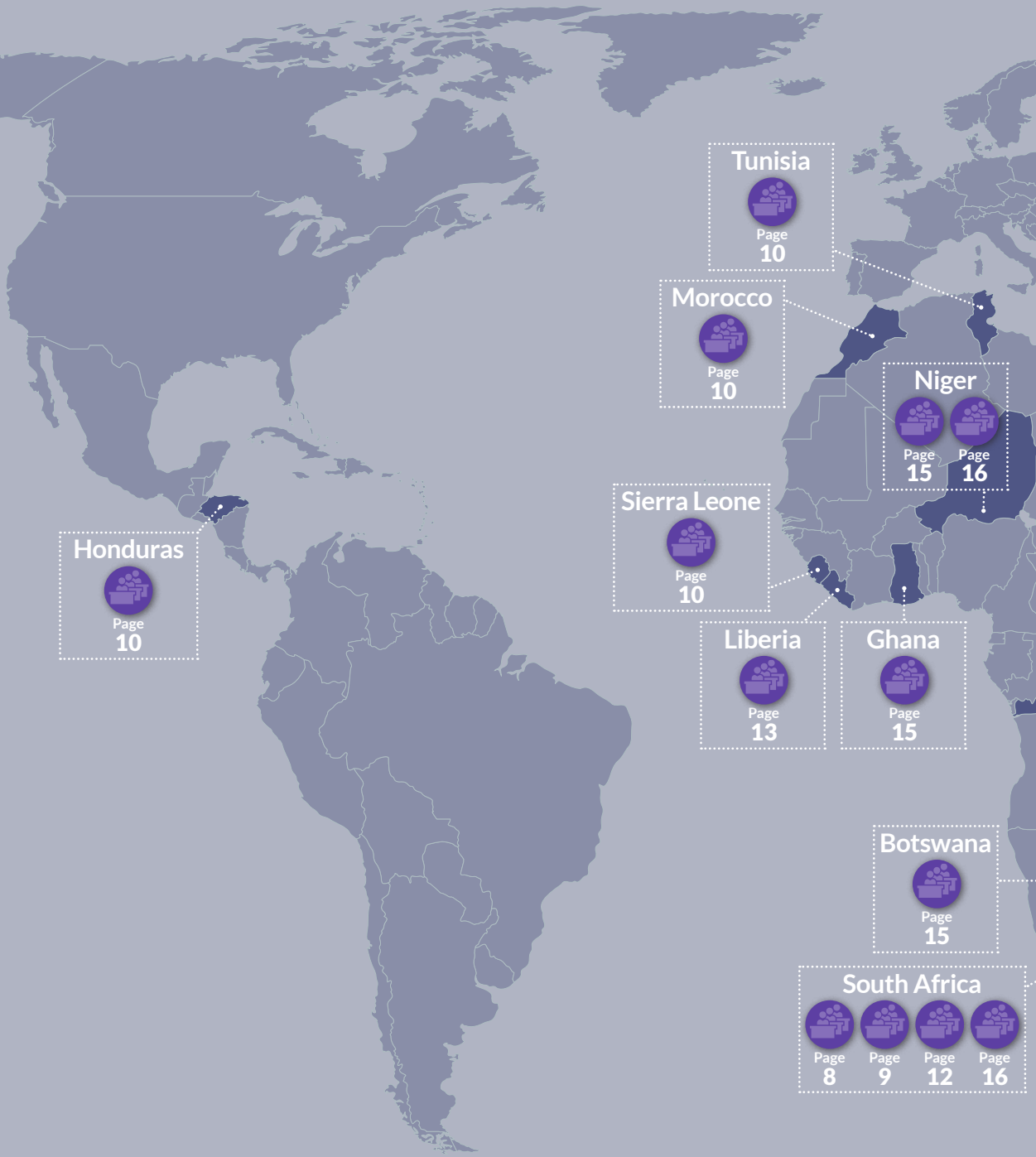




\section{Outcomes in Education Systems}

The Raising Learning Outcomes in Education Systems Research Programme

aims to provide policymakers and practitioners with evidence on how to improve learning and understanding of how these will translate to their specific context and institutions. It further aims to inform relevant local, national, and global policy and programme decisions.

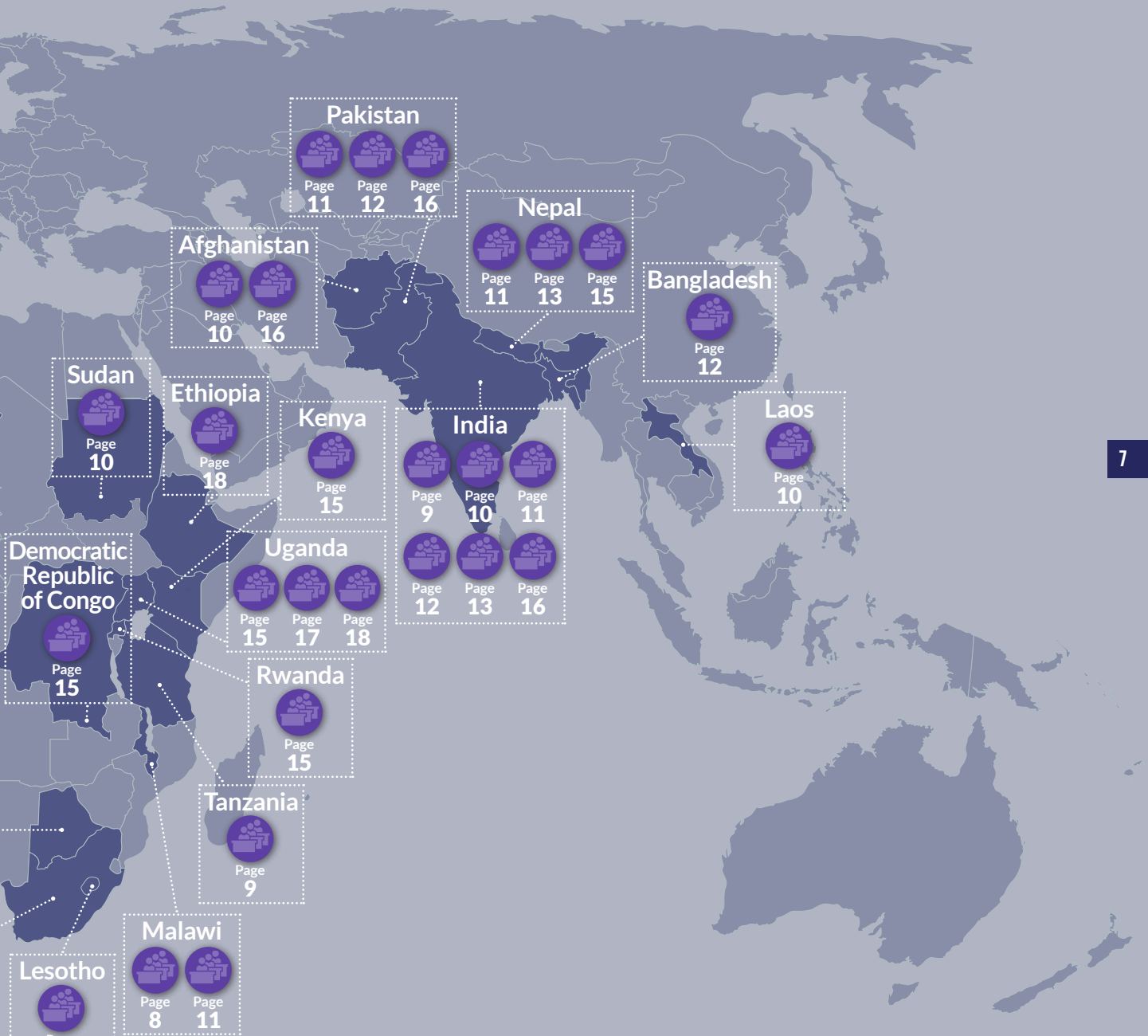

10
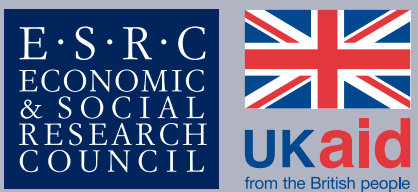

Research jointly supported by the ESRC and DFID 


\section{Glossary of projects}

Projects are listed below in alphabetical order of their titles, and include the name and institutional affiliation of the Principal Investigator. To explore the research further, including information on research partners, the intended policy and practice implications, or for more information about The Impact Initiative for International Development Research, visit: www.theimpactinitiative.net

All the projects listed in this glossary were funded by the ESRC-DFID Raising Learning Outcomes in Education Systems Research Programme which aims to provide policymakers and practitioners with concrete ideas on how to improve learning and understanding of how these will translate to their specific context and institutions, and to demonstrably inform relevant policy and programme decisions.

Accountability, capacity and trust to improve learning outcomes in South Africa: a systems approach (South Africa)

September 2017 - August 2021

Melanie Ehren

UNIVERSITY COLLEGE LONDON, UK

Trust is not only conditional to a country's general welfare but is also a key condition for the improvement of education. This research explores the relationship between accountability, capacity and trust, and how these factors can affect learning outcomes in South Africa. The study aims to identify the conditions in which accountability leads to system improvement; particularly, how capacity and trust are essential enablers for external accountability to have a positive impact on school staff, teaching, and learning in schools.
Accountability for gender equality in education: critical perspectives on an indicator framework for the SDGs

(Malawi, South Africa)

January 2018 - April 2020

Elaine Unterhalter

UNIVERSITY COLLEGE LONDON, UK

This study seeks to develop an indicator framework for gender equality in education that can support the work of the Sustainable Development Goal (SDG) for education, particularly the monitoring of the SDG targets on gender and education. The research focuses on Malawi and South Africa, where policies intending to address gender inequality and to support the expansion of education provision face complex challenges of implementation. 


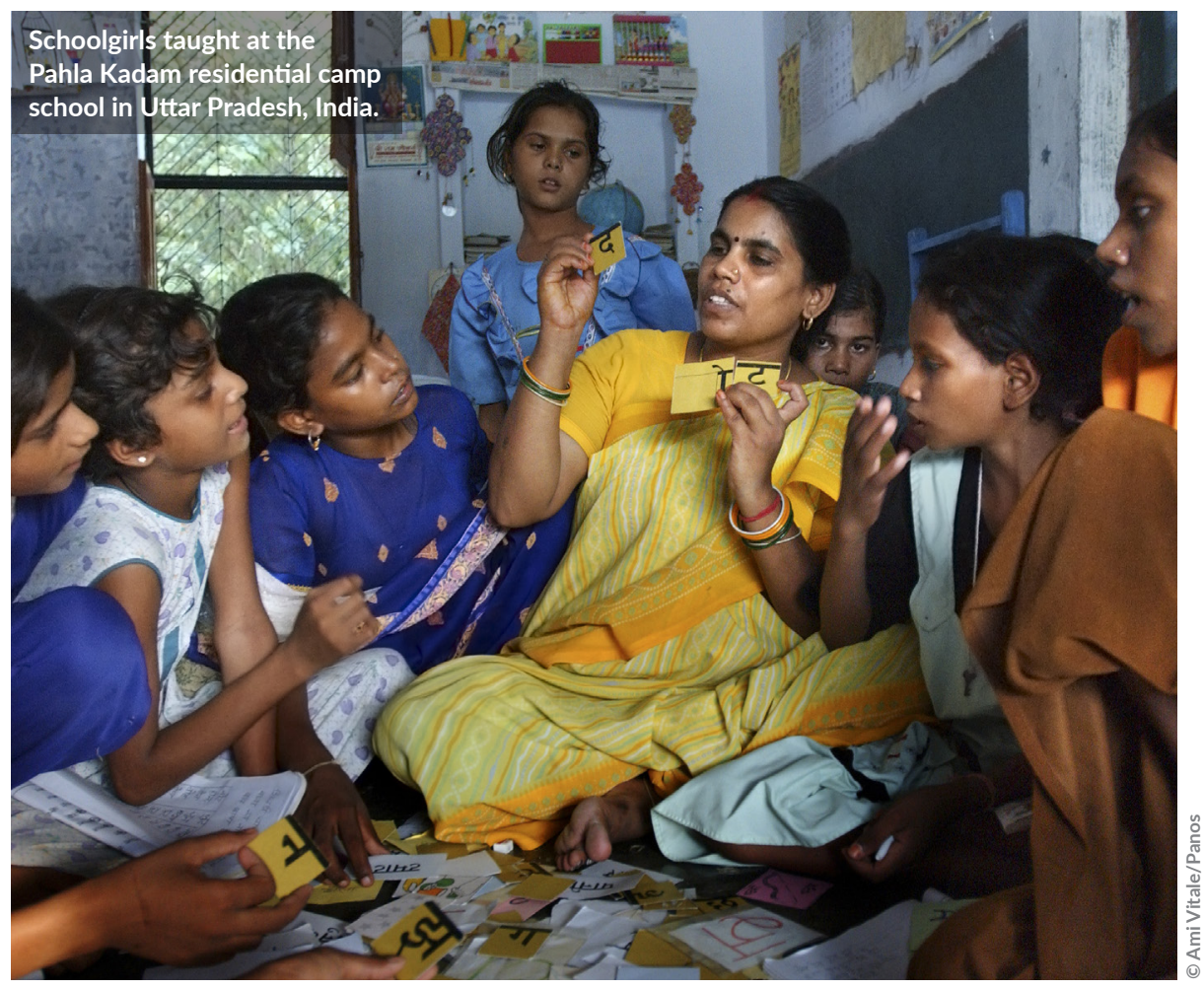

Assessment for Learning in Africa (AFLA): improving pedagogy and assessment for numeracy in foundation years

(South Africa, Tanzania)

April 2016 - March 2019

Therese N. Hopfenbeck

UNIVERSITY OF OXFORD, UK

This project focuses on improving low levels of basic numeracy through the development of teachers' and teacher trainers' pedagogical and assessment skills in extremely deprived urban areas in South Africa and Tanzania.
Can schools' accountability for learning be strengthened from the grass roots? Investigating the potential for community-school partnerships in India

(India)

January 2018 - March 2021

Ricardo Sabates

UNIVERSITY OF CAMBRIDGE, UK

This project aims to understand whether and how school accountability for learning can be improved from the grass roots. It assesses the impact of a community-based intervention in rural India which aims to 
engage with local school actors (teachers, headteachers, administrators, and school management committees), with the goal of improving children's foundational learning in the classroom.

\section{Constructing a global framework for analysis of social exclusion from and within learning systems}

(Afghanistan, India, Morocco, Sierra Leone, Sudan, Tunisia)

May 2015 - April 2016

Parul Bakhshi

WASHINGTON UNIVERSITY IN ST. LOUIS, USA

This research explored the gap that exists between idealistic education policies that look at participation

in education rather than individual educational achievement. It developed a framework that deciphers processes of social exclusion not just from, but also within, learning systems and applied this to data from Afghanistan, India, Morocco, Sierra Leone, Sudan, and Tunisia.

\section{Disadvantage and participation} accountability processes: theory and evidence from school development and management committees in

\section{Karnataka, India}

(India)

March 2018 - February 2021

Sayantan Ghosal

UNIVERSITY OF GLASGOW, UK

How do parents from disadvantaged groups in India engage with school development and management committees to improve the learning environment for their children? This project is constructing a new theoretical model and collecting quantitative and qualitative evidence to assess the impact of a pro-poor training programme to encourage active participation and critical engagement.

\section{Education systems, aspiration and} learning in remote rural settings

(India, Laos, Lesotho)

September 2016 - April 2019

Nicola Ansell

BRUNEL UNIVERSITY LONDON, UK

Through ethnographic research with young people in remote rural areas of Lesotho, India and Laos, this project investigates the processes through which schooling shapes young people's aspirations, and how young people's aspirations shape their engagement with schooling and their learning outcomes.

\section{Examining effective teaching in rural} Honduran secondary schools

\section{(Honduras)}

July 2015 - June 2018

Erin Murphy-Graham

UNIVERSITY OF CALIFORNIA, BERKELEY, USA

This study built upon existing positive evidence on the Sistema de Aprendizaje (Tutorial Learning System) model for secondary schools in Honduras. It sought to identify elements that support effective teaching in poor, rural, geographically isolated communities. Furthermore, by following up with a cohort of young people surveyed in 2008, it examined whether there are linkages between 
improved quality education and successful transition to adulthood.

\section{Facilitating innovative growth of} low-cost private schools: experimental evidence from Pakistan (Pakistan)

March 2016 - February 2018

Asim ljaz Khwaja

HARVARD UNIVERSITY, USA

In countries such as Pakistan, private schools now command a significant and rapidly increasing share of the education market. This project sought to explain how interventions associated with alleviating constraints of access to financing or to affordable education support services (both individually and together) affect learning outcomes, enrolment, and school profitability in low-cost private schools.

\section{Improving curriculum and teaching} methods to influence policy and increase the quality of ECDE provision for children with

\section{disabilities in Malawi}

(Malawi)

June 2015 - May 2018

Paul Lynch

UNIVERSITY OF BIRMINGHAM, UK

This study looked at ways to increase the quality of early childhood development and education (ECDE) provision for children with disabilities in Malawi. It explored how to improve the early childhood curriculum and teaching methods of pre-school carers, and how community-based childcare centres can provide institutional support to help meet family goals that support their children.

\section{Improving learning: developing}

measures of accountability and evaluating their association with students' gains in achievement in Nepal (Nepal)

January 2017 - March 2020

Dirgha Ghimire

UNIVERSITY OF MICHIGAN, USA

This project seeks to develop and validate measures of accountability, and to use those measures in an analysis of the determinants of accountability and its association with students' gains in achievement. It does so by building on the Chitwan Valley Family Study which has collected data over 20 years in the Western Chitwan Valley of Nepal.

Improving school governance and learning outcomes at scale: a randomised evaluation of the Madhya Pradesh School Quality Assessment programme (India)

March 2016 - August 2018

Karthik Muralidharan

UNIVERSITY OF CALIFORNIA, SAN DIEGO, USA This project carried out a randomised evaluation of the Madhya Pradesh School Quality Assessment programme in India - one of the most ambitious recent attempts by a developing country government to improve education 
governance at scale. The study assessed the impact of the programme through the collection and processing of data from schools, including on teacher absence and effort, classroom observations of pedagogy, and student academic outcomes.

\section{Inclusive higher education learning outcomes for rural and township youth: developing a multi- dimensional capabilities-based higher education index (South Africa)}

September 2016 - August 2020 Melanie Jane Walker

UNIVERSITY OF THE FREE STATE, SOUTH AFRICA

The research aims to develop an integrated, policy-oriented higher education index based on theorisation of pathways to learning outcomes from access to post-graduation - that emphasise equality and quality for lowincome young people from rural areas and townships in South Africa. The project uses mixed methods to investigate what learning outcomes are valued by students themselves over time and by other stakeholders, why they are valued, and whether and how they are achieved.

\section{Investing in our future: the early childhood intervention and parental involvement in Bangladesh}

(Bangladesh)

May 2016 - May 2020

Asadul Islam

MONASH UNIVERSITY, AUSTRALIA
This project examines the impact of programmes which aim to improve both short- and long-term outcomes of rural children in Bangladesh. These include a programme that prepares pre-school children for primary school, workshops to enable parents to support their child's learning, and monthly cash transfers to reduce financial stress.

\section{Learning outcomes and teacher effectiveness for children facing multiple disadvantages, including those with disabilities: India and}

\section{Pakistan}

(India, Pakistan)

July 2015 - June 2018

Pauline Rose

UNIVERSITY OF CAMBRIDGE, UK

Focusing on India and Pakistan, this project identified the ways in which teaching affects children's learning, and so inform governments on the strategies needed to support children who face multiple disadvantages. The research paid particular attention to children with disabilities, who are most likely to be excluded from learning.

\section{Literacy development with deaf} communities using sign language, peer tuition, and learner-generated online content: sustainable educational innovation

\section{(India)}

June 2015 - May 2016

Ulrike Zeshan

UNIVERSITY OF CENTRAL LANCASHIRE, UK 
India has one of the world's largest deaf communities, yet there is a critical shortage of teachers with sign language skills. The project focused on innovative methods of teaching literacy to deaf learners in India through peer-guided teaching combined with online and in-class learning.

\section{Multilingualism and multiliteracy: raising learning outcomes in challenging contexts in primary schools across India}

(India)

March 2017 - April 2020

lanthi Maria Tsimpli

UNIVERSITY OF CAMBRIDGE, UK

This project examines the causes of low educational outcomes in schools in India, where many children fail to achieve basic literacy and numeracy levels. It has a particular focus on the medium of instruction and its relationship to the language(s) used at a child's home, and how gender differences and geographical disparities have an effect on learning outcomes. It also explores how each of these factors affects learning, critical thinking, and problem-solving in multilingual primary school children.

\section{Organizational Perspectives on} Accountability and Learning (OPAL): school management models and the social impact of schooling in Mumbai and Kathmandu

(India, Nepal)

October 2017 - October 2020
Robin Shields

UNIVERSITY OF BATH, UK

Focusing on India and Nepal, the project investigates how the accountability of schools differs according to the school management model and whether accountability is linked to differences in learning outcomes. For this, the study looks at accountability relationships across a range of stakeholders, including parents, teachers and school management, and goes beyond cognitive outcomes to look at the effect of accountability on schools' social contribution in terms of social inclusion and participation.

\section{Partnership schools for Liberia:} impact on accountability mechanisms and education

\section{(Liberia)}

January 2018 - January 2020

Justin Sandefur

CENTER FOR GLOBAL DEVELOPMENT, USA

The Liberian Ministry of Education announced in early 2016 that it would contract the operation of some government primary schools to a group of private companies. This project studies the effect of this programme, comparing schools that have been delegated to management by private operators to schools that remain under government management. It examines accountability relationships of teachers to operators; teachers and operators to parents; and private operators to the Ministry of Education. 


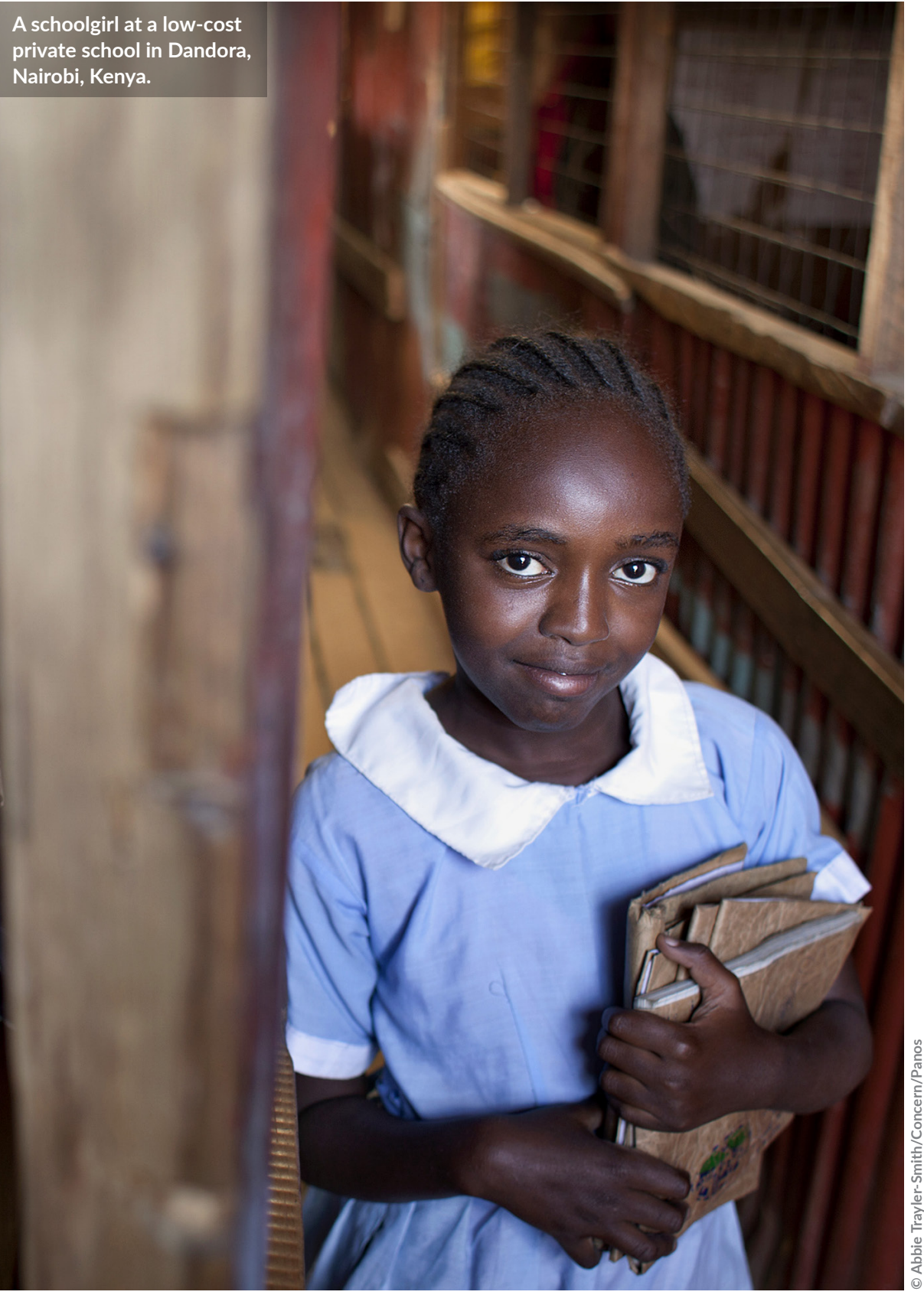


Pedagogies for critical thinking: innovation and outcomes in African

\section{higher education}

(Botswana, Ghana, Kenya)

April 2015 - March 2018

Tristan McCowan

UNIVERSITY COLLEGE LONDON, UK

This project aimed to expand the existing evidence base around how pedagogical practices affect the development of critical thinking at African higher education institutions. It did so by investigating the impact of locally generated pedagogical interventions on student critical thinking ability in Botswana, Ghana, and Kenya.

\section{Peer-to-peer deaf multiliteracies:}

research into a sustainable approach to education of deaf children and young adults in the global South (Ghana, Nepal, Rwanda, Uganda) July 2017 - June 2020

Ulrike Zeshan

UNIVERSITY OF CENTRAL LANCASHIRE, UK

This is an extension of the one-year pilot study Literacy development with deaf communities using sign language, peer tuition, and learner-generated online content: sustainable educational innovation. Extending the project into four more countries (Ghana, Nepal, Rwanda and Uganda), this peer-led project is helping address the huge resource gap of trained teachers who are fluent in Indian sign language by promoting educational changes from within the deaf community, underpinned by digital and mobile learning and teaching.

\section{Promoting children's learning}

outcomes in conflict-affected

countries: evidence for action in Niger

(Niger)

July 2017 - June 2019

John Lawrence Aber

NEW YORK UNIVERSITY, USA

This follow-on study to Promoting children's learning outcomes in conflict-affected countries: generating, communicating, and incorporating evidence for impact aims to adapt and test novel, low-cost, targeted interventions designed to lift constraints on children's academic learning and socio-emotional wellbeing through schooling in Niger. It also seeks to understand both mechanisms of impact and contexts of implementation.

\section{Promoting children's learning outcomes in conflict-affected} countries: generating, communicating, and incorporating evidence for impact (Democratic Republic of Congo)

\section{April 2015 - April 2016}

John Lawrence Aber

NEW YORK UNIVERSITY, USA

In the context of the Democratic Republic of Congo, this project undertook analyses of data from a large-scale, experimental evaluation of a school-based intervention programme, 'Healing Classrooms'. The intervention included an integrated teacher training/curricular development reform aimed at promoting academic and socio-emotional learning in conflictaffected settings. 


\section{Rights and Accountability in the Indian System of Education (RAISE)}

(India)

May 2017 - March 2020

Caroline Dyer

UNIVERSITY OF LEEDS, UK

This project focuses on learning outcomes for disadvantaged learners in India. It investigates how learning outcomes for disadvantaged children are shaped by the norms and interests, modes of participation, and regulatory roles among multiple actors from across the home, community, school, and bureaucracies.

\section{Strengthening schools} accountability mechanisms through participation: addressing education quality and equity in Afghanistan and Pakistan (Afghanistan, Pakistan) January 2018 - December 2021 Jean-Francois Trani WASHINGTON UNIVERSITY IN ST. LOUIS, USA This research develops, implements, and evaluates a social accountability intervention - combined with inclusive education training - engaging parents, teachers, and children. It aims to assess the intervention's impact on basic cognitive and psychosocial skills of learners as well as parents' expectations and engagement, and teachers' confidence with regards to inclusion of children with disabilities in the contexts of Afghanistan and Pakistan.
Succeeding against the odds: understanding resilience and exceptionalism in high-functioning township and rural primary schools in South Africa

(South Africa)

May 2016 - November 2018

Servaas Van Der Berg

STELLENBOSCH UNIVERSITY, SOUTH AFRICA

The objective of this study was to understand resilience and exceptionalism in high-functioning township and rural primary schools in South Africa. The research looked at which practices associated with school leadership and management were driving the difference between the high-performing schools and the average/low-performing schools in these settings.

\section{Technology, monitoring and teacher support in Niger}

(Niger)

October 2017 - September 2020 Jenny Aker

TUFTS UNIVERSITY, USA

This research tests the use of low-cost technology via mobile phones in an adult education programme in Niger. The intervention includes monitoring teachers' attendance and providing long-distance pedagogical support to teachers. It further aims to assess the intervention on a smaller scale in primary schools to understand whether the dynamics of teacher monitoring and support are different in this setting and with governmental institutions. 


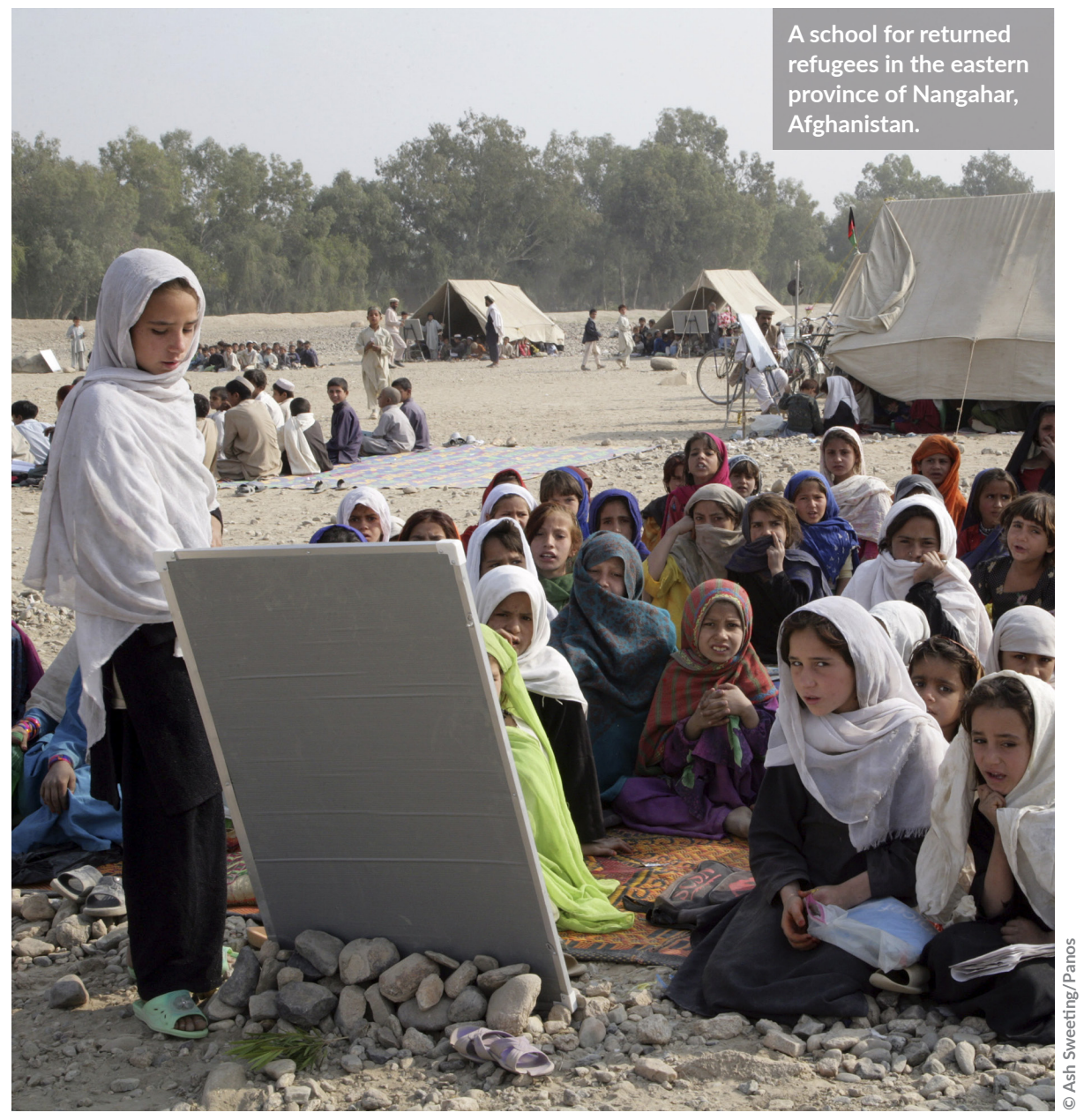

The Literacy Laboratory Project (LLP) under the Northern Uganda Literacy

\section{Program}

\section{(Uganda)}

May 2015 - April 2019

Rebecca Thornton

UNIVERSITY OF ILLINOIS, USA

Using longitudinal data, this research aims to identify whether, with the right combination of training, teaching and learning materials, teachers can be supported to effectively teach literacy - even in rural, under-resourced, overcrowded classrooms. The study also explores economic approaches to implementation at scale to determine value-for-money impacts on pupil learning and teacher performance in African schools. 


\section{Toward the development of a}

rigorous and practical classroom observation tool: the Uganda

\section{secondary school project}

\section{(Uganda)}

April 2015 - April 2016

Edward Seidman

NEW YORK UNIVERSITY, USA

This research sought to develop and validate an innovative, affordable, scalable, and practical tool for assessing teacher practices and classroom processes. It tested the tool in the context of Uganda, with the additional aim of identifying its potential for providing feedback to teachers.

\section{Transforming the pedagogy of STEM}

\section{subjects}

\section{(Ethiopia)}

June 2015 - May 2018

Vanessa Kind

DURHAM UNIVERSITY, UK

The study looked to address some of the constraints of traditional teachercentred 'lecturing' by devising strategies to improve the quality of science teaching. The project trained primary school science teachers across Ethiopia to use teacherstudent and student-student dialogue to support the learning of physics. 


\section{ESRC-DFID's Strategic Partnership - research evidence for policymakers and practitioners}

ormed in August 2005, the UK's Economic and Social Research Council (ESRC) and the Department for International Development (DFID) Strategic Partnership funds world class scientific research on a broad range of topics. The partnership contributes to a robust conceptual and empirical basis for development and funds the Joint Fund for Poverty Alleviation Research, the Raising Learning Outcomes in Education Systems Programme and the Growth Research Programme (DEGRP).

- The Raising Learning Outcomes in Education Systems Programme aims to provide policymakers and practitioners with concrete ideas on how to improve learning and understanding of how these will translate to their specific context and institutions, and to demonstrably inform relevant policy and programme decisions. The research funded through this programme focuses on how to raise learning outcomes for all by considering equity (including gender and disability) as well as quality dimensions of education. The current programme runs from January 2014 to March 2022.

Visit www.esrc.ac.uk/eddev for further information.

- The Joint Fund for Poverty Alleviation Research aims to enhance the quality and impact of social science research with the goal of reducing poverty amongst the poorest countries and peoples of the world. The primary aim of the scheme is to fund scientific research with potential impact on policy and practice for poverty reduction. Since 2005 , the fund has enabled a portfolio of 172 projects $^{3}$ on issues ranging from child poverty and inequality, secure livelihoods, disability, inequality in education, health system reform, climate adaptation and much more besides. The most recent funding phase is due to complete in 2021.

Visit www.esrc.ac.uk/international-development for further information.

- The Growth Research Programme (DEGRP) focuses on issues related to economic growth in low-income countries (LICS).

Visit www.esrc.ac.uk/international-development for further information. 


\section{THE IMPACT INITIATIVE}

\section{For International Development Research}

This booklet provides an overview of education research encompassing 30 projects focused in 24 countries which have been enabled by the UK's Economic and Social Research Council (ESRC) and the Department for International Development (DFID) Strategic Partnership.

The Impact Initiative for International Development Research seeks to connect policy makers and practitioners with the world class social science research supported by the ESRC-DFID Strategic Partnership, maximising the uptake and impact of research from:

(i) The Joint Fund for Poverty Alleviation Research, and (ii) The Raising Learning Outcomes in Education Systems Research Programme. We seek to identify synergies between these programmes and their grant holders, support them to exploit influencing and engagement opportunities, and facilitate mutual learning.

The Impact Initiative is a collaboration between the Institute of Development Studies (IDS) and the University of Cambridge's Research for Equitable Access and Learning (REAL) Centre.

Email: info@theimpactinitiative.net

Website: www.theimpactinitiative.net

\% @the_Impact_Init \#impactlessons \#policies4 